06,04

\title{
Особенности поляризации пьезоэлектрической керамики на основе ниобата натрия
}

\author{
(C) О.В. Малышкина ${ }^{1}$, М. Али ${ }^{1}$, А.И. Иванова ${ }^{1}$, И.А. Чернышова ${ }^{2}$, Д.В. Мамаев ${ }^{1}$ \\ ${ }^{1}$ Тверской государственный университет, \\ Тверь, Россия \\ ${ }^{2}$ Санкт-Петербургский государственный университет, \\ Санкт-Петербург, Россия \\ E-mail: Olga.Malyshkina@mail.ru \\ Поступила в Редакцию 3 июля 2021 г. \\ В окончательной редакции 3 июля 2021 г. \\ Принята к публикации 7 июля 2021 г.
}

Проведены сравнительные исследования пироэлектрических свойств и структурных особенностей керамик ниобата натрия и ниобата натрия-калия, полученных при различных технологических условиях синтеза материала ниобата натрия. Методом рентгенофазового анализа выявлено существование дополнительной фазы с химической формулой $\mathrm{NaNb}_{10} \mathrm{O}_{18}$ в образцах керамики ниобата натрия, не проявляющих сегнетоэлектрических свойств. Показано, что температурные режимы синтеза материала ниобата натрия определяют характер макроскопической поляризации образцов как чистого ниобата натрия, так и ниобата натрия-калия.

Ключевые слова: пьезоэлектрическая керамика, бессвинцовые материалы, поляризация, пироэлектрический эффект.

DOI: 10.21883/FTT.2021.11.51593.159

\section{1. Введение}

Исследования сегнетоэлектрических керамик на основе ниобата натрия (NN) начались в то же время [1], когда и содержащих свинец материалов [2,3]. Промышленное применение нашли последние, благодаря высоким значениям пьезомодулей и другим диэлектрическим характеристикам. Введение ограничений на применение свинецсодержащих материалов, документально отраженное в законодательстве Европейского союза (Directiv 2002/95/EC) и в техническом регламенте Евразийского экономического союза „Об ограничении применения опасных веществ в изделиях электротехники и радиоэлектроники“ (ТР ЕАЭС 037/2016) заставило вернуться в начале XXI века к поиску модифицированных составов на основе не содержащих свинец керамик, в том числе и на основе ниобата натрия [4-8]. Поскольку основное промышленное применение имеют модифицированные составы цирконата титаната свинца [9], новый этап изучения бессвинцовых пьезоэлектрических керамик привел к обширным исследованиям влияния модификаторов щелочных и редкоземельных металлов и построению многокомпонентных систем на основе ниобата натрия-калия (KNN) [10]. Система KNN была выбрана, в первую очередь, благодаря ряду оптимистических публикаций $[11,12]$, и возможностью построения для нее фазовой диаграммы [13]. В то же время, наиболее эффективные керамики на основе KNN получены в области полиморфного перехода между тетрагональной и орторомбической фазами, что приводит к возникновению эффекта фазопереходной усталости даже при незначительном нагревании керамик, и существенно ограничивает спектр возможных практических применений $[14,15]$. Достаточно широко исследуются другие твердые растворы на основе керамики ниобата натрия $[1,11,13]$. Не модифицированный ниобат натрия, несмотря на то что его изучают достаточно долго $[1,16]$, продолжает оставаться интересным объектом для исследования. Это обусловлено большим количеством разнородных фазовых переходов данной керамики [16-19] в температурном интервале $360-640^{\circ} \mathrm{C}$, что дает возможность влиять на ее свойства, варьируя в незначительных пределах температуру синтеза данного материала. Действительно, как нами было показано ранее [20], изменение температуры синтеза состава ниобата натрия, даже без добавления модифицирующих добавок, приводит к существенному изменению свойств конечных образцов. Они могут существовать при комнатной температуре в стабильной сегнетоэлектрической фазе, тогда как, согласно литературным данным, кристалл ниобата натрия является модельным антисегнетоэлектриком [21].

Целью настоящей работы являлось определение структурных механизмов появления антисегнетоэлектрической фазы в керамике ниобата натрия и исследование однородности поляризованного состояния образцов керамик NN и KNN. Последнее актуально не только в научном плане, но и в практическом отношении, поскольку для применения пьезоэлектрических керамик 
определяющим является однородность макроскопической поляризации.

\section{2. Методы получения и исследования}

Образцы керамики ниобата натрия и ниобата натриякалия были получены методом твердофазного синтеза и исследованы на оборудовании Центра коллективного пользования Тверского государственного университета.

Твердофазный синтез материала $\mathrm{NaNbO}_{3}$ для получения керамики NN осуществлялся тремя различными способами: одиночный синтез при температуре $\left(T_{\text {synth }}\right)$ $650^{\circ} \mathrm{C}$ (NN650) или $700^{\circ} \mathrm{C}(\mathrm{NN} 700)$; двойной синтез оба при $T_{\text {synth }}=700^{\circ} \mathrm{C}(\mathrm{NN700-700)}$ и первый при $T_{\text {synth }}=650^{\circ} \mathrm{C}$, второй при $T_{\text {synth }}=700^{\circ} \mathrm{C}(\mathrm{NN} 650-700)$. Для керамики $\mathrm{KNN}$ материал $\mathrm{KNbO}_{3}$ синтезировался двойным синтезом (первый при $T_{\text {synth }}=650^{\circ} \mathrm{C}$, второй при $\left.T_{\text {synth }}=700^{\circ} \mathrm{C}\right) . \mathrm{NaNbO}_{3}$ также двойным синтезом, но с различными температурами синтеза: I партия: обе температуры $700^{\circ} \mathrm{C}$ (KNN1), II партия: первый синтез при $T_{\text {synth }}=650^{\circ} \mathrm{C}$, второй при $T_{\text {synth }}=700^{\circ} \mathrm{C}(\mathrm{KNN} 2)$.

Образцы прессовались в форме таблеток диаметром $10.4 \mathrm{~mm}$ и толщиной $1-2 \mathrm{~mm}$ под давлением 5 атмосфер. Спекание образцов осуществлялось при температуре $1100^{\circ} \mathrm{C}$ в течение $4 \mathrm{~h}$.

Структура и элементный состав исследовались методом растровой электронной микроскопии (SEM) с использованием микроскопа JEOL JSM-6610LV (Япония). Для определения структуры зерен использовался режим вторичных электронов (SEI) с ускоряющим напряжением $10-14 \mathrm{kV}$, рабочим расстоянием $11 \mathrm{~mm}$, током зонда $5 \mathrm{pA}$. Исследование с помощью отраженных (ВЕС) электронов позволили выявить композиционный (по элементному составу) контраст. Анализ элементного состава проводился в аналитическом комплексе сканирующего электронного микроскопа с помощью спектрометра с дисперсией по энергии рентгеновских квантов модели INCA Energy + фирмы Oxford Instruments (Великобритания). Система энергодисперсионного рентгеновского микроанализа Oxford INCA Energy 350 позволяет определять массовую и атомную доли (концентрацию) химических элементов в образцах.

Фазовый состав определялся методом порошковой рентгенографии на дифрактометре ДРОН-7, излучение $\mathrm{Cu}-\mathrm{K} \alpha$. Интерпретация полученных рентгенограмм была проведена на базе Научного парка СПбГУ (РЦ РДМИ) в программных комплексах PDXL и TOPAS версия 5.0.

Присутствие и направление спонтанной поляризации в образцах определялось методом динамического пироэффекта [22].

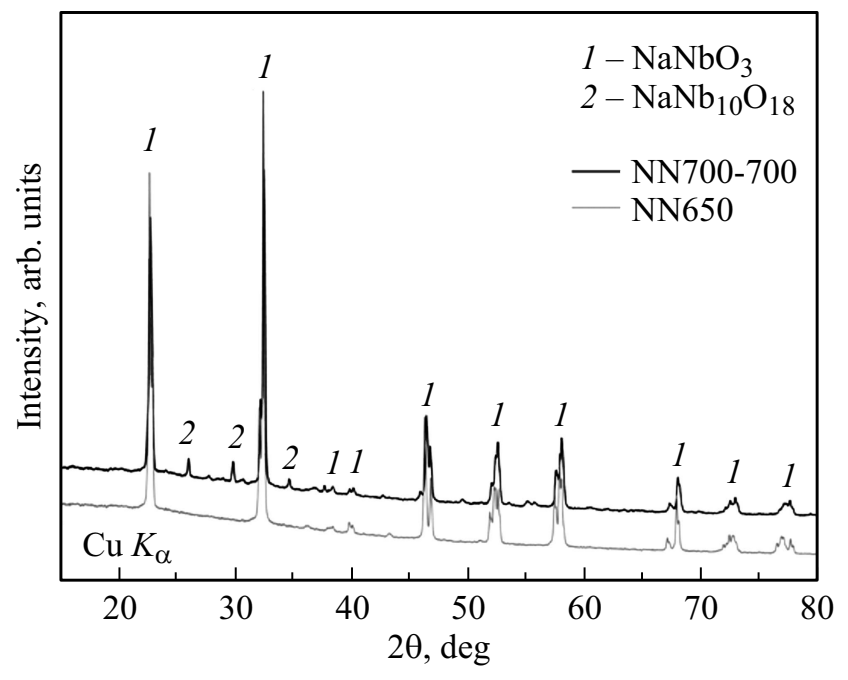

Рис. 1. Рентгенограмма образцов NN650 и NN700-700.

\section{3. Экспериментальные результаты и их обсуждение}

Рентгенофазовый анализ образцов NN показал существование в этих образцах двух фаз (рис. 1).

Основная фаза - $\mathrm{NaNbO}_{3}$, соответствует минералу луешиту, имеющему структуру типа перовскита $[23,24]$. Структуру луешита можно представить в виде каркаса из октаэдров $\left[\mathrm{NbO}_{6}\right]$, в полостях которого находятся атомы $\mathrm{Na}[25]$.

Дополнительная фаза - $\mathrm{NaNb}_{10} \mathrm{O}_{18}$. Существование фазы $\mathrm{NaNb}_{10} \mathrm{O}_{18}$ и ее кристаллографические характеристики впервые были рассмотрены авторами [26]. Валентность ниобия в данной химической формуле $3.5+$. Такая валентность, по всей видимости, означает, что структурная единица содержит две или более (но четное число) формульных единиц, в которых валентность атомов $\mathrm{Nb}$ чередуется $(3+$ и $4+)$. Возможные степени окисления $\mathrm{Nb}(5,4,3,2$ и 1) такую валентность допускают.

Присутствие дополнительной фазы зависит от условий синтеза материала NN. Так, у образцов с одиночным синтезом (NN650 и NN700), она отсутствует. Тогда как для образца NN700-700 ее вхождение около 10\%. Увеличение температуры спекания до $1400^{\circ} \mathrm{C}$ не изменило процентное содержание дополнительной фазы.

Исследования структуры зерен и сегнетоэлектрических свойств показали их существенную зависимость от присутствия в материале NN дополнительной фазы. Так, размер зерен у образцов без дополнительной фазы (рис. $2, a, b)$ на порядок больше чем у образцов с $10 \%$ содержанием (рис. 2,c).

В ходе анализа элементного состава нами были получены и обработаны спектры, регистрируемые с поверхности образцов в разных зернах. Если у образцов NN650 и NN700 наблюдается незначительный разброс 


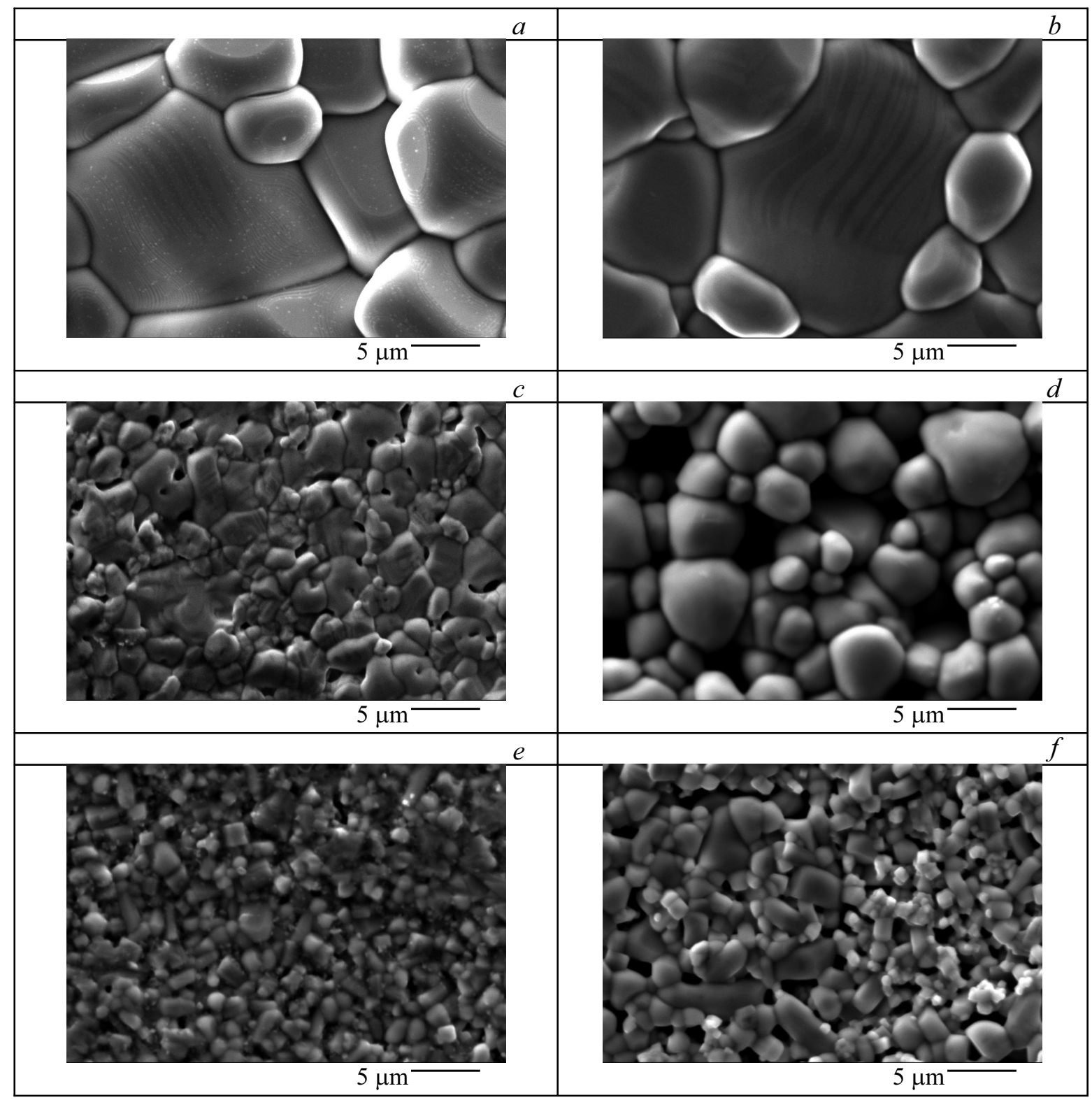

Рис. 2. РЭМ-изображения поверхности образцов NN650 (a), NN700 (b), NN700-700 (c), NN650-700 (d), KNN1 (e) и KNN2 (f). Масштабная метка $5 \mu \mathrm{m}$.

содержания элементов $\mathrm{Na}, \mathrm{Nb}$ и $\mathrm{O}$ по зернам, то у материала NN700-700, ряд зерен содержит значительно меньшее количество Na. Содержание (в молярных процентах) элементов для материалов $\mathrm{NN}$, рассчитанное по химической формуле и среднее значение, полученное в эксперименте, приведено в табл. 1. У керамик NN650, NN700, NN650-700 и в большинстве зерен керамик NN700-700 содержание элементов $\mathrm{Na}, \mathrm{Nb}$ и О мало отличается от химической формулы $\mathrm{NaNbO}_{3}$, наблюдается только незначительное уменьшение количества атомов натрия по сравнению с атомами ниобия и повышенное содержании кислорода. В то же время, в зернах с пониженным содержанием $\mathrm{Na}$ (материал NN700-700) соотношение $\mathrm{O}: \mathrm{Na}: \mathrm{Nb}$ не соответствует химическим формулам $\mathrm{NaNb}_{10} \mathrm{O}_{18}$ и $\mathrm{NaNbO}_{3}$, следовательно в этих зернах присутствуют обе фазы.

Таким образом, проведенные структурные исследования показали, что наличие у образцов керамик NN650 и NN700 переключаемой электрической поляризации, и ее отсутствие у керамики NN700-700, что было показано нами ранее [20], связано с отсутствием (присутствием) в структуре образцов фазы $\mathrm{NaNb}_{10} \mathrm{O}_{18}$.

Поскольку в основе большинства практических применений сегнетоэлектрических керамик в качестве пьезоакустических преобразователей используются продольные или поперечные колебания в переменных электрических полях, то для их реализации необходимы рабочие тела, имеющую однородную поляризацию по 
Таблица 1. Содержание элементов в материалах NN, молярные \%

\begin{tabular}{c|c|c|c}
\hline Параметр & $\mathrm{O}$ & $\mathrm{Na}$ & $\mathrm{Nb}$ \\
\hline Хим. формула $\mathrm{NaNbO}_{3}$ & 60 & 20 & 20 \\
\hline \multicolumn{4}{c}{$\mathrm{NN650,} \mathrm{NN700}^{\text {NN650-700 }}$} \\
\hline Среднее в эксперименте & 61 & 18 & 21 \\
\hline NN700-700 & 63 & 17 & 20 \\
\hline Среднее в эксперименте & 63 \\
\hline Среднее в эксперименте 1 & 62 & 18 & 20 \\
\hline Среднее в эксперименте 2 & 72 & 9 & 19 \\
\hline Хим. бормула NaNb $_{10} \mathrm{O}_{18}$ & 62 & 3.5 & 34.5
\end{tabular}

Таблица 2. Зависимость величины пиротока керамик на основе NN от условий синтеза

\begin{tabular}{|c|c|c|}
\hline \multirow{2}{*}{$\begin{array}{c}\text { Условия синтеза } \\
\mathrm{NaNbO}_{3}\end{array}$} & \multicolumn{2}{|c|}{ Пироток, $10^{-10} \mathrm{~A}$} \\
\hline & Сторона $-\mathrm{P}_{\mathrm{s}}$ & Сторона $+\mathrm{P}_{\mathrm{s}}$ \\
\hline \multicolumn{3}{|c|}{ NN } \\
\hline $\begin{array}{c}1 \text { синтез } 650^{\circ} \mathrm{C} \\
1 \text { синтез } 700^{\circ} \mathrm{C} \\
2 \text { синтеза } 700^{\circ} \mathrm{C} 700^{\circ} \mathrm{C} \\
2 \text { синтеза } 650^{\circ} \mathrm{C} 700^{\circ} \mathrm{C}\end{array}$ & $\begin{array}{l}0.7 \\
0.4 \\
5.2 \\
0.52\end{array}$ & $\begin{array}{l}0.56 \\
0.16 \\
0.48 \\
0.52\end{array}$ \\
\hline \multicolumn{3}{|c|}{$\mathrm{KNN}$} \\
\hline $\begin{array}{l}2 \text { синтеза } 650^{\circ} \mathrm{C} 700^{\circ} \mathrm{C} \\
2 \text { синтеза } 700^{\circ} \mathrm{C} 700^{\circ} \mathrm{C}\end{array}$ & $\begin{array}{l}0.64 \\
2.12\end{array}$ & $\begin{array}{l}0.64 \\
0.14\end{array}$ \\
\hline
\end{tabular}

толщине образца. Для анализа состояния поляризации в образцах был использован метод динамического пироэффекта [22], который позволяет определять не только наличие спонтанной поляризации, но и ее направление в образце. Перед измерением пиротока, образцы поляризовались в постоянном электрическом поле $1.5 \mathrm{kV} / \mathrm{mm}$. В качестве источника теплового потока использовался ИК-лазер мощностью $60 \mathrm{~mW}$. Измерения проводились на сторонах образцов, соответствующих положительному $\left(+\mathrm{P}_{\mathrm{s}}\right)$ и отрицательному $\left(-\mathrm{P}_{\mathrm{s}}\right)$ концам вектора спонтанной поляризации (табл. 2).

Не смотря на то что образцы керамики NN650 и NN700, согласно [20], имеют макроскопическую поляризацию, фиксируемую по петле диэлектрического гистерезиса, распределение поляризации по толщине поляризованных в постоянном электрическом поле образцов неравномерно. В этих образцах, как и у NN700-700, существует градиент поляризации, направленный от стороны $-\mathrm{P}_{\mathrm{s}}$ к стороне $+\mathrm{P}_{\mathrm{s}}$. Причем у образца NN700-700 и величина градиента, и значение пиротока на стороне $-\mathrm{P}_{\mathrm{s}}$ значительно превышают аналогичные значения, наблюдаемые для образцов NN650 и NN700. Поскольку вид петель диэлектрического гистерезиса керамики NN700-700 допускает наличие в образце анитисегнетоэлектрического состояния [20], можно предположить, что именно оно способствует столь неравномерному перераспределению объемного заряда, индуцирующего дополнительную поляризацию, внутри образца.

Поскольку в качестве альтернативной замены материала ЦТС, рассматривается керамика KNN, то однородность поляризации была проверена и на поляризованных образцах этого материала. Материал KNN700-700 имеет градиент поляризации, аналогичный составу NN700-700 (табл. 2). Из чего следует, что именно технологический процесс синтеза материала ниобата натрия является причиной наличий в конечных образцах градиента поляризации.

Интересно отметить, что однородное распределение поляризации по толщине образцов (табл. 2) удалось получить в образцах керамик NN650-700 и KNN2, т. е. у тех составов, материал ниобата натрия для которых синтезировался по одинаковой технологии двойного синтеза с температурами $650^{\circ} \mathrm{C}$ первый синтез и $700^{\circ} \mathrm{C}$ второй.

Если сравнивать со структурой промышленной керамики ЦТС [27,28], то размер зерен именно образцов NN650-700 и KNN2 (рис. 2, $d$ и $f$ ) максимально приближен к структуре, наблюдаемой у образцов ЦТС.

\section{4. Заключение}

Проведенные исследования показали, что варьируя температурный режим синтеза материала ниобата натрия можно существенно влиять на сегнетоэлектрические свойства керамик на его основе. Так, несмотря на то что природный поликристаллический материал NN (леушит) имеет антисегнетоэлектрические свойства [24], нам удалось синтезировать керамику NN, имеющую при комнатной температуре сегнетоэлектрические свойства.

В процессе исследований выявлено, что одиночный синтез, с одной стороны, позволяет получать керамику NN с четко наблюдаемыми сегнетоэлектрическими свойствами, как на микро, так и на макроскопическом уровне. С другой стороны, однородной поляризации в постоянном электрическом поле для этих образцов добиться не удалось. Возможно, в данном случае, отрицательную роль играет большой размер зерен (до $20 \mu \mathrm{m})$. Здесь необходимо отметить, что размер зерен промышленных образцов керамики ЦТС не превышает 5-6 $\mu \mathrm{m}$. Именно такой размер зерен наблюдался в настоящей работе у образцов NN650-700 и KNN2, в которых удалось получить однородное по толщине распределение поляризации, о чем свидетельствует одинаковая величина пироотклика, наблюдаемая на противоположных сторонах образца.

В то же время материалы с достаточно большим градиентом поляризации (NN700-700 и KNN1), после 
выяснения физических причин проявления такого градиента, могут найти практическое применение в пьезоэлектрических датчиках с изгибными колебаниями, в которых на настоящее время используются специально сконструированные биморфы.

\section{Конфликт интересов}

Авторы заявляют, что у них нет конфликта интересов.

\section{Список литературы}

[1] L. Egerton, D.M. Dillon. J. Am. Ceram. Soc. 42, 9, 438 (1959).

[2] Г.А. Смоленский. ЖТФ 20, 2, 137 (1950).

[3] Г.А. Смоленский. Усп. физ. наук 62, 1, 41 (1957).

[4] B. Malic, A. Bencan, T. Rojac, M. Kosec. Acta Chim. Slov. 55, 4, 719 (2008).

[5] В.И. Иваненко, Э.П. Локшин, О.Г. Громов, В.Т. Калинников. Синтез сегнетоэлектрических и люминесцентных сложных оксидов редких элементов. Изд-во Кольского научного центра РАН, Апатиты (2009). 153 с.

[6] Л.А. Резниченко, И.А. Вербенко, К.П. Андрюшин. Фазовые переходы, упорядоченные состояния и новые материалы 11, 30 (2013).

[7] J. Wu, D. Xiao, J. Zhu. Chem. Rev. 115, 7, 2559 (2015).

[8] J. Rodel, K.G. Webber, R. Dittmer, W. Jo, M. Kimura, D. Damjanovic. J. Eur. Ceram. Soc. 35, 1659 (2015).

[9] Материалы пьезокерамические ОСТ II 0444-87. Дата введения с 01.01.1988.

[10] Sh. Zhang, R. Xia, Th.R. Shrout. J. Electroceram. 19, 251 (2007).

[11] Y. Saito, H. Takao, T. Tani, T. Nonoyama, K. Takatori, T. Homma, T. Nagaya, M. Nakamura. Nature 432, 7013, 84 (2004). doi: 10.1038/nature03028.

[12] L.E. Cross. Nature 432, 7013, 24 (2004).

[13] B. Malic, J. Koruza, J. Hrescak, J. Bernard, K. Wang, J. Fisher, A. Bencan. Materials 8, 811 (2015).

[14] E. Hollenstein, D. Damjanovic, N. Setter. J. Eur. Ceram. Soc. 27, 13-15, 4093 (2007).

[15] K. Higashide, K.-I. Kakimoto, H. Ohsato. J. Eur. Ceram. Soc. 27, 13-15, 4107 (2007).

[16] H.D. Megaw. Ferroelectrics 7, l-4, 87 (1974).

[17] Yu.I. Yuzyuk, P. Simon, E. Gagarina, L. Hennet, D. Thiaudiere, V.I. Torgashev, S.I. Raevskaya, I.P. Raevskii, L.A. Reznitchenko, J.L. Sauvajol. J. Phys: Condens. Matter. 17, 33, 4977 (2005).

[18] В.С. Бондарев, А.В. Карташев, М.В. Горев, И.Н. Флёров, М.С. Молокеев, С.И. Раевская, Д.В. Суздалев, И.П. Раевский. ФТТ 55, 4, 752 (2013).

[19] Н.Н. Крайник. Изв.АН СССР. Сер. физ. 28, 4, 643 (1964).

[20] O.V. Malyshkina, M. Ali, E.V. Barabanova, A.I. Ivanova. Ferroelectrics 567, 1, 197 (2020).

[21] P. Vousden. Acta Cryst. 4, 6, 545 (1951).

[22] В.А. Головнин, И.А. Каплунов, О.В. Малышкина, Б.Б. Педько, А.А. Мовчикова. Физические основы, методы исследования и практическое применение пьезоматериалов. Техносфера, М. (2013). 272 с.

[23] A.C. Sakowski-Cowley, K. Łukaszewicz, H.D. Megaw. Acta Cryst. B 25, 851 (1969).
[24] R.H. Mitchell, B.J. Kennedy K.S. Knight. Phys. Chem. Minerals 45, 77 (2018).

[25] Д.О. Мищук, О.И. Вьюнов, О.В. Овчар, А.Г. Белоус. Неорган. материалы 40, 12, 1508 (2004).

[26] J. Kohler, A. Simon. Z. Anorg. Chem. 572, 7 (1989).

[27] С.И. Пугачев, И.А. Эмбиль, О.В. Малышкина, А.А. Топчиёв. Морские интеллектуальные технологии 2, 2(24), 60 (2014).

[28] О.В. Малышкина, А.Ю. Елисеев, В.А Головнин, А.В. Дайнеко, А.И. Иванова, Е.В. Барабанова. Поверхность. Рентгеновские, синхротронные и нейтронные исследования $\mathbf{9}$, 40 (2015).

Редактор Т.Н. Василевская 